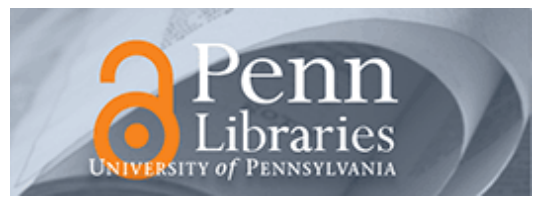

University of Pennsylvania

ScholarlyCommons

Marketing Papers

Wharton Faculty Research

$1-1-1994$

\title{
Effects of portfolio planning methods on decision making: experimental results
}

\author{
J. Scott Armstrong \\ University of Pennsylvania, armstrong@wharton.upenn.edu \\ Roderick J. Brodie \\ University of Auckland, r.brodie@auckland.ac.nz
}

Follow this and additional works at: https://repository.upenn.edu/marketing_papers

Part of the Statistics and Probability Commons

\section{Recommended Citation}

Armstrong, J. S., \& Brodie, R. J. (1994). Effects of portfolio planning methods on decision making:

experimental results. Retrieved from https://repository.upenn.edu/marketing_papers/15

Postprint version. Published in International Journal of Research in Marketing, Volume 11, Issue 1, January 1994, pages 73-84.

Publisher URL: http://dx.doi.org/10.1016/0167-8116(94)90035-3

This paper is posted at ScholarlyCommons. https://repository.upenn.edu/marketing_papers/15

For more information, please contact repository@pobox.upenn.edu. 


\title{
Effects of portfolio planning methods on decision making: experimental results
}

\author{
Abstract \\ Subjects ( $n=1015)$ working individually in the role of managers were asked to choose between \\ investment opportunities that would either double their investment or cause the loss of half of it. Six \\ administrators ran experiments on 27 occasions in six countries over a five-year period. Information \\ about the BCG matrix increased the subjects' likelihood of selecting the project that was clearly less \\ profitable. Of subjects exposed to the BCG matrix, $64 \%$ selected the unprofitable investment. Of subjects \\ who used the BCG matrix in their analysis, $87 \%$ selected the less profitable investment. \\ Disciplines \\ Statistics and Probability \\ Comments \\ Postprint version. Published in International Journal of Research in Marketing, Volume 11, Issue 1, \\ January 1994, pages 73-84. \\ Publisher URL: http://dx.doi.org/10.1016/0167-8116(94)90035-3
}


International Journal of Research in Marketing, 11, (1994), 73-84, North-Holland

\title{
Effects of Portfolio Planning Methods on Decision Making: Experimental Results*
}

\author{
J. Scott Armstrong \\ The Wharton School, University of Pennsylvania, Philadelphia, PA 19104, USA \\ Roderick J. Brodie \\ Department of Marketing, University of Auckland, Auckland, New Zealand
}

\begin{abstract}
Subjects ( $\mathrm{n}=1015)$ working individually in the role of managers were asked to choose between investment opportunities that would either double their investment or cause the loss of half of it. Six administrators ran experiments on 27 occasions in six countries over a five-year period. Information about the BCG matrix increased the subjects' likelihood of selecting the project that was clearly less profitable. Of subjects exposed to the BCG matrix, 64\% selected the unprofitable investment. Of subjects who used the BCG matrix in their analysis, $87 \%$ selected the less profitable investment.
\end{abstract}

\section{Introduction}

Marketing texts currently advocate portfolio planning methods. Consultants continue to apply portfolio methods. Decision makers claim to use various portfolio matrix classification schemes for analyzing investment opportunities. Portfolio matrix methods are widely taught; for example, Morrison and Wensley (1981) surveyed business schools in the UK and concluded that most schools include matrix methods in their marketing and marketing strategy courses. Despite this continuing use of portfolio methods, we have been unable to find any empirical evidence to support their use. To address this issue, we conducted a series of experiments to determine the effects of matrix methods on decision making. The paper first provides a brief examination of portfolio planning methods and a discussion of some problems with matrix classification methods. We then describe the experiments.

\section{Brief examination of portfolio planning methods}

Portfolio planning methods have been used for strategic decision making for over 20 years. $\sim$ They are presented as diagnostic aids and as prescriptive guides for selecting strategic options (Kotler, 1984). The general idea is to classify positions of products along two dimensions: attractiveness of the market and ability of the product to compete within that market. Wind and Mahajan (1981) provide a review of matrix methods.

Some researchers have pointed out weaknesses in . the premises behind portfolio methods. In particular, they have addressed problems for the Boston Consulting Group (BCG) matrix (e.g., Day, 1986, pp. 182-192). The BCG matrix measures market attractiveness by market growth rate, and it assesses the firm's ability to compete by. its relative market share. The BCG matrix assumes a causal relationship between market share and profitability. Wensley (1981) argues that the BCG matrix lacks internal consistency; he also claims that there is little empirical evidence to support a causal relationship between market growth and profits. Jacobson and Aaker (1985) also present evidence that challenges the causal assumption. Morrison and Wensley (1991) provide a comprehensive review of previously published evaluations of the BCG matrix.

\footnotetext{
* Diana Day, Martin Gimpl, Bernard Guerin, David Jobber, Terence Oliva, David J. Reibstein, Juergen Ringbeck, Steven P. Schnaars, Allan Singer, Jerry Wind, Arch Woodside and two anonymous referees provided valuable comments. Wayne Cartwright, Martin Gimpl, Juergen Ringbeck, and Donald Scott ran some of the experiments. Jennifer L. Armstrong and Phan Lam provided editorial assistance.
} 
.The use of the BCG matrix is inhibited by difficulties in measurement of market growth rates and relative market shares. One reason for this is that market boundaries are often difficult to fix. As a result, different matrix methods are likely to yield different recommendations for the same situation. Wind et al. (1983) demonstrated that decisions based on the BCG matrix are sensitive to choice of the methods of measuring market share and growth rates. Morrison and Wensley (1991) claim that the scope of the BCG matrix ignores other relevant strategic issues.

Although the BCG matrix and other matrix methods have little theoretical or empirical support, one can find arguments in their favor (e.g., Haspeslagh, 1982). One argument is that managers often neglect to use a rational economic approach. Instead; they use unstructured judgmental processes that may be inconsistent with profit maximization. They may base their decisions on power or emotional factors, such as inclusion of sunk costs (Arkes and Bulmer, 1985). As a result, many of their decisions are irrational from the viewpoint of profit maximization. Thus, portfolio planning methods, such as the BCG matrix, may lead managers to make decisions that are less irrational than those they make when using unaided judgment. For example, if a powerful corporate manager uses the BCG matrix for analysis, her tendency to support a dying division with unwis e investments may be overcome.

The original developers of the BCG matrix have heeded warnings about misuse of this matrix as a prescriptive aid (Morrison and Wensley, 1991). As one of them stated " . . today it [the matrix] is misused and overexposed. It can be a helpful tool, but it can also be misleading..." (quoted in Morrison and Wensley, 1991, p. 118). Despite their warnings, much literature (e.g., McKiernan, 1992) continues to argue that the BCG matrix provides a useful starting point for strategic analysis.

Given the substantial literature about portfolio matrices, it was surprising that we were able to find only one empirical study on the value of the BCG matrix. This was a field study by Capon et al. (1987, pp. 316-317). It found that firms using the BCG matrix methods reported a lower return on capital than those not using them. Of course, one can propose other explanations for lower returns, such as that unprofitable firms turn to the BCG matrix for salvation.

Despite the lack of favorable evidence and warnings by its original developers, the BCG matrix has been widely adopted by firms (Zallocco et al., 1983; Verhage and Waarts, 1988). Capon et al. (1987, p. 69) present evidence that it is the most widely used portfolio method in US firms. Morrison and Wensley (1991), in their survey of teachers at 34 business schools in the UK, found that the BCO matrix is taught at all schools and that warnings are seldom discussed.

Matrix methods are judged to be successful by those who use them. Haspeslagh (1982), in a survey of Fortune 1000 companies, found that almost all respondents believed that their use of formal portfolio planning methods had a positive impact.

We conducted surveys of MBA students at the Wharton School, University of Auckland, University of Toronto, and University of Canterbury; 95\% of our respondents had some knowledge of the BCG matrix. When asked, "To what extent do you believe that the BCG matrix is useful for strategic decision-making in marketing?", $66 \%$ of the 175 respondents believed that the BCG matrix would "produce better (or, significantly better) decisions under certain circumstances." However, these respondents were unable to describe circumstances in which the BCG matrix would be useful. Also, when asked "what evidence do you have for your opinions on the BCG matrix?", most said "What the textbook (or instructor) had stated." Only five percent said that the BCG matrix would produce poorer decisions. No one was able to cite empirical evidence; this was not surprising, of course, as we also have been unable to find such support.

\section{Further problems with use of matrix methods}

Matrix methods provide simple rules of thumb as decision aids. These rules often employ labels for different types of products (e.g., dogs, stars, and cash cows). Because labels are intuitively appealing and easy to use, they may lead decision makers to overlook profit maximization. For example, labels in the BCG matrix might create misleading "mental accounts." Tversky and Kahneman (1981) use their "theater tickets problem" to show how mental accounting can mislead people: 
"Imagine that you have decided to see a play and paid the admission price of $\$ 10$ per ticket. As you enter the theater you discover that you have-lost the ticket. The seat was not marked and the ticket cannot be recovered. Would you pay $\$ 10$ for another ticket?"

Most subjects (54\%) said that they would not purchase another ticket. Now consider the following question:

"Imagine that you have decided to see a play where the admission is $\$ 10$ per ticket. As you enter the theater you discover that you have lost a $\$ 10$ bill. Would you still pay $\$ 10$ for the play?"

In this case, most (88\%) subjects said that they would pay for the play.

The fact that money has been placed in a category, the "ticket account," leads some decision makers to treat the money differently. Might a mental budgeting phenomenon occur when a decision maker uses matrix classifications that have been developed for strategic planning? For example, a product in the Cash Cow account might imply "money should be removed and spent elsewhere," a Star might suggest a "product on which money should be spent," and a Dog implies "do not spend money on this product." Moreover, labels in the BCG matrix might introduce emotional terms into the decision-making process. For example, would managers want to work on a product known as a "Dog"?

In a survey of UK business school teachers by Morrison and Wensley (1991), 26\% thought that the BCG matrix was misleading. The reverse side of this is that most did not think it was misleading:

\section{Procedure}

We conducted a series of laboratory experiments to investigate whether decision makers might be misled by portfolio methods when making an investment decision. Although laboratory experiments have been subject to increasing skepticism and their rate of publication in- management journals has been decreasing, they provide a valid and useful approach-in many situations (Griffin and Kacmarl 1991). Furthermore. Locke (1986) found a high correspondence between results from artificial laboratory experiments and realistic field studies in research on organizational behavior. In our case, laboratory experiments offer controls that were not possible in the field study by Capon et al. (1987).

Our experiments examined the original and best known version of the BCG matrix. This section describes hypotheses, situations, experimental treatments, subjects, and administrative procedures.

\section{Hypotheses}

The hypotheses were:

Hypothesis 1 (Hl) Knowledge of a matrix method is likely to interfere with decisions concerning long-term profit maximizing, and

Hypothesis 2 (H2) Use of a matrix method in the analysis is likely to interfere with decisions concerning long-term profit maximizing.

The rationale for $\mathrm{H} 1$ is that people with knowledge of matrix methods might overlook basic economic principles and apply the technique when it is clearly detrimental to profit maximizing. The second hypothesis, $\mathrm{H} 2$, suggests that if decision makers use the BCG matrix in their analysis, they are likely to apply it inappropriately. In other words, the second hypothesis goes beyond aware ness of the technique to find what happens when the technique is used.

\section{Situations}

We based the situation on an investment decision in a firm because we believed this to be a common type of decision. While we wanted a situation that seemed realistic, the type of investment decision was arbitrarily selected. In keeping with the traditional approach to laboratory experiments, we used a simple design. However, to add realism to the situation, we included details. We did not expect these details to bias results. 
Subjects had to choose between two different opportunities. One project involved a money saving invention and the other in volved an investment in advertising. We designed these situations to have correct answers. The materials said that the objective of the company was "to maximize profits," and subjects received sufficient informations to meet this objective. It is interesting that Henderson, the developer of the BCG matrix, had stated that "Such a single chart, with a projected position for five years out, is sufficient alone to tell a company's profitability..." (Morrison and Wensley, 1991).

To determine whether the BCG matrix would mislead people, we wrote the situation such that the profitable investment was labeled a "Dog" (low market growth and low market share); this investment . would, in rough terms, double over the next ten years. The other alternative was a bad investment in the "Star" category (high growth and high share); here, about half the investment would be lost over the next ten years. The problem description said that the decision had no negative side effects and that other products were not affected by this decision.

The description contained sufficient information so that the profit maximizing decision should be obvious to subjects. However, the implications of the BCG matrix should conflict with this decision. The issue then is whether subjects would apply the BCG matrix blindly. In other words, might the BCG matrix interfere with decision making in cases where -the profit maximizing decision is obvious? Note that this design does not allow for the BCG matrix. to produce 'superior decisions. ${ }^{1}$

We provided the following description to all subjects. To avoid possible confusion with existing firms, we chose product names that were obviously fictitious. In addition, we used mnemonic names (Culp for the Cow, Sunbars as the Star, and Digits as the Dog):

"Conglomerate, Inc. has stated its objective as "to maximize profits" and you agree with this. The company currently has three major products -Culp, Sunbars, and Digits.

Culp has a very large market share (10 times the market share of its leading competitor), and it has a large sales volume. However, it is in a market that is growing at only two percent per year. ${ }^{2} 2$ It produces about $\$ 2,000,000$ in cash flow and profits are about $\$ 1,600,000$ after taxes.

Sunbars has a modest current sales volume (1/4 that of Culp), a relative market share of 1.5 (versus its leading competitor), and it is in a market that is growing 20\% per year. Cash flow from Sunbars is currently negligible. Sunbars produces an after-tax profit of $\$ 500,000$ per year. Future prospects for Sunbars are good.

Finally, Digits, while also having a modest sales volume, is in a market that is not growing at all, and it has a small market share, about 1/5 of the leading competitor. Digits, has barely adequate profits of $\$ 50,000$ per year and it has negligible cash flow.

Recently, an inventor has found a better way to make Digits. He has come to your company with a proposal. It calls for an investment of $\$ 1,500,000$. The forecasts are that, while this invention would not affect final demand, it would produce cost savings after taxes of about $\$ 500,000$ per year for the next ten years. After the initial outflow of $\$ 1,500,000$, the invention would yield a net cash flow of $\$ 500,000$ per year. Your sales forecasts for Digits show it holding steady for the next ten years. You are highly confident about both the cost and sales forecasts. The Sunbars division also has an opportunity it feels would strengthen its position in the market. It proposes a new advertising campaign. Since Sunbars are sold by direct mail, initial small-scale mailings have given you an excellent idea of its success. The $\$ 1,800,000$ investment would generate after-tax profits of $\$ 400,000$ the first year, $\$ 300,000$ the second, and $\$ 100,000$ per year for the next eight years. Cash flow would he approximately the same as profits. After thorough

\footnotetext{
${ }^{1}$ We considered adding a second situation where the BCG might produce better decisions, but we unable devise such a test within the limits of our budget. We challenged colleagues to devise such a situation, but they were also unsuccessful.

${ }^{2}$ Growth rates are in constant or real dollars (after adjusting for inflation).
} 
investigation, you are convinced that these investments would not adversely affect the community, the employees, the customers, or the retailers. In other words, there are no negative side effects. The two investment possibilities have no impact on other products in this firm."

We pretested the above description with many subjects. Our intent was to develop a case that was extreme, yet realistic, simple, and free of bias. We had planned to add complexity to the problem description to learn if subjects would eventually get confused and blindly rely upon the BCG matrix. As it turned out, subjects were misled by the initial version, so pretesting led to few changes. ${ }^{3}$

\section{Treatments}

We gave subjects in the control group the description of the situation along with the following role:

"You are in charge of corporate investments. You have only two opportunities that are feasible now. You must make a decision today. Corporate management has said that only one of these investments can be funded."

The control group received no other information.

We gave the following instructions to the experimental groups:

"Recently you attended a course given about the [either BCG or Net Present Value] method of corporate planning. You came away from that course with a summary paper [which was attached]. You've made many investment decisions in the past and you are now wondering whether the method might help you to analyze the current investments."

We obtained the description of the BCG matrix from Kotler [1984, pp. 51-54]. This ensured that participants in the BCG group would be aware of the matrix when examining this problem. It also ensured that their knowledge of this matrix would be more accurate than if they were to rely only upon memory. Furthermore, the description is typical of what would be provided to many mangers in the real world.

The description of Net Present Value was as follows:

"Economic theory says that you should select the in vestment that produces the highest long-term return on investment. Your focus is on the overall economic success of your company considering all of your products and markets. When making these decisions, it is not only the expected value, but also the risk that is important. Here is one way: one, calculate the present value (PV) of the income profit stream; two, do the same for the capital investments. Then subtract the present value (PV) of investments from the PV of profits to get net present value of the investment."

This NPV group also received a table of discount factors using a $12 \%$ cost of capital.

\section{Subjects}

The 1015 subjects came from a variety of management programs. They were primarily from New Zealand (622) and the US (269), but also from Malaysia (43), Argentina (38), Canada (34), and West Germany (9). We used subjects who were participants in educational sessions discussing marketing planning, thus avoiding self-selection bias. All participants responded, although one percent of them were unable to reach a decision.

${ }^{3}$ Interestingly, when we circulated drafts of this paper, some readers indicated a need for added complexity. However, we were unable to have them specify what details should he added. Nor could we get them to describe how such details might relate to the hypotheses. 
The 333 undergraduate subjects had, little prior experience. However, 407 subjects were MBAs with at least two years of business-related work experience. The other 275 subjects were in middle-management courses, and they had more business experience and less formal education than the MBAs.

\section{Administration}

The experiments were administered by six faculty members on 27 occasions from 1985 through 1990 . They were done in group settings, but subjects worked individually. Subjects were instructed not to put their names on the materials. Almost all subjects finished well within the 30-minute period allowed.

Subjects were randomly assigned to a treatment using a systematic sampling plan. However, the number of responses from each treatment was not always equal for two reasons. First, because the sessions focused on the BCG matrix, we often gave the BCG version to more subjects. Second, as the study progressed, alternative explanations arose; to address these, we introduced new treatments.

We also asked subjects to complete a follow-up questionnaire after making their decisions. This questionnaire asked subjects to describe the "reason for my decision." These responses, along with calculations or comments that they made on the experimental materials, allowed us to code the approaches the subjects used to reach their decisions. We were able to code the process for $70 \%$ of the subjects. The other $30 \%$ typically listed a few facts or issues before coming to a decision.

Generally, each administrator coded responses for the experiments that he conducted. Coding of subjects' replies was simple. Nevertheless, to ensure that coding was not a source of error, a research assistant who was not aware of the correct answer, nor of the hypotheses, independently coded a subsample of the replies $(n=263)$. She obtained identical classifications for $94 \%$ of the items.

A debriefing session followed completion of the follow-up questionnaire. The adminis trator explained the purpose of the study, and provided summaries of prior results. Thus, subjects could see how their responses compared with others. A general discussion then followed where subjects asked questions.

\section{Results}

The most surprising result was that in $44.7 \%$ of the decisions, subjects in control groups failed to select what was designed to be an obviously more profitable investment. The traditional economic prescriptions taught in business schools, that one should use NPV and should compare only those things that vary with the decision, were apparently ignored by these subjects.

Our experiments showed that the availability of information on the BCG matrix did mislead subjects. They typically chose the Star (Sunbars), which was much less profitable than the Dog (Digits). Overall, 63.5\% of those in BCG treatment groups chose the unprofitable project, compared with $44.7 \%$ in control groups. This difference between subjects in BCG and control groups is statis tically significant at $\mathrm{p}<0.01$ (using Z-score for difference between proportions). The results are consistent with what one would expect from mental budgeting and they support H1. Specifically, information about the planning matrix was detrimental to decisions concerning long-term profit maximizing. Table 1 summarizes results. ${ }^{4}$

\footnotetext{
${ }^{4}$ In addition, a Spanish translation was produced and administered in Uruguay. This used only the BCG treatment. Of the 15 managers, ten (67\%) selected the unprofitable decision. This is , comparable to the $63.5 \%$ in Table 2 . This treatment was administered by Professor Hector Bogo, IDEA, 1850 Moreno, 1094 Buenos Aires, Argentina
} 
Table 1

Decisions by treatment and method used

\begin{tabular}{|c|c|c|c|c|c|}
\hline \multirow{2}{*}{$\begin{array}{l}\text { Treatment } \\
\text { presented to subjects }\end{array}$} & \multirow{2}{*}{$\begin{array}{l}\text { Method } \\
\text { used by subjects }\end{array}$} & \multicolumn{2}{|l|}{ Decision } & \multirow[t]{2}{*}{ Subjects } & \multirow{2}{*}{$\begin{array}{l}\text { Percent } \\
\text { sunbars (Star) }\end{array}$} \\
\hline & & sunbars (Star) & digits (Dog) & & \\
\hline \multirow[t]{4}{*}{ BCG } & $\mathrm{BCG}$ & 148 & 25 & 173 & \\
\hline & Profit $^{a}$ & 8 & 58 & 66 & \\
\hline & Other $^{\mathrm{b}}$ & 32 & 25 & 57 & \\
\hline & Subtotal & 188 & 108 & 296 & 63.5 \\
\hline \multirow[t]{4}{*}{ Control } & $\mathrm{BCG}$ & 18 & 2 & 20 & \\
\hline & Profit & 15 & 97 & 112 & \\
\hline & Other & 69 & 27 & 96 & \\
\hline & Subtotal & 102 & 126 & 228 & 44.7 \\
\hline \multirow[t]{4}{*}{ NPV } & BCG & 18 & 0 & 18 & \\
\hline & Profit & 24 & 133 & 157 & \\
\hline & Other & 44 & 13 & 57 & \\
\hline & Subtotal & 86 & 146 & 232 & 37.1 \\
\hline
\end{tabular}

${ }^{\mathrm{a}}$ Refers to NPV or other calculations based on profit.

${ }^{\mathrm{b}}$ These responses did not provide enough information about how the decision was made.

Subjects given information about NPV made fewer unprofitable decisions $(37.1 \%)$ than did the control group subjects (44.7\%). This difference was significant at $\mathrm{p}<0.05$, but the amount of improvement was modest.

We examined whether subjects used the approaches encountered in their "training courses" and how these affected their decisions. Of the 296 subjects in the BCG treatment, 173 (58.4\%) decided that the BCG matrix was relevant and used it explicitly. Only $8.3 \%$ of those in other groups used the BCG matrix, although, as shown below, almost all subjects were probably familiar with it prior to this experiment. About $68 \%$ of those in the NPV group used profits as the basis for their decisions; this can be compared with $49 \%$ of those in the control group.

We then examined what decision was made when a subject used different methods in his/her analysis: Table 2 summarizes these results. When subjects used the BCG matrix in their analysis, $86.8 \%$ selected the star, the unprofitable project. In contrast, only $15.3 \%$ of those using profit calculations selected the star. These are substantial differences in decision making for subjects facing the identical problem. This result supports $\mathrm{H} 2$; use of a matrix method in the analysis is likely to interfere with decisions involving long-term profits. Interestingly, of those subjects whose decision process could not be coded, $69.5 \%$ chose the unprofitable decision. We suspect that there was an intuitive appeal to "sticking with your best product."

Table 2

Decisions summarized by method used by subjects

\begin{tabular}{lrrrl}
\hline Method & \multicolumn{2}{l}{ Decision } & Subjects & $\begin{array}{l}\text { Percent } \\
\text { used by subjects }\end{array}$ \\
\cline { 2 - 3 } Sunbars (Star) & Digits (Dog) & & Sunbars (Star) \\
\hline BCG & 190 & 29 & 219 & 86.8 \\
Profit & 66 & 366 & 432 & 15.3 \\
Other & 171 & 75 & 246 & 69.5 \\
& & & & \\
Subtotal & 427 & 470 & 897 & 47.6 \\
\hline
\end{tabular}

\section{Discussion}

We expected that subjects in control groups would maximize profits. As noted, $44.7 \%$ of them failed to do so. This occurred even though we provided all necessary information to determine that one decision was clearly 
profitable and the other was clearly unprofitable. This result for the control groups is surprising considering the emphasis given to profit maximization in many business school courses. (Their primary problem with profit maximizing, based on our examination of their analyses, was that they seemed to be unaware that, when examining a project, one should examine only those factors that vary with the decision.) Subjects who took' the less profitable decision mentioned using "strategic and marketing considerations." Many of them said that they based their decision on going with their better product. This suggests that these subjects' intuitions about how to make investment decisions are more closely related to assump tions behind the matrix methods than behind traditional economic analysis.

Of course, students are also exposed to the BCG matrix at business schools and through business publications. To assess the extent of this exposure, we conducted surveys of MBA students at the Wharton School, University of Auckland, University of Toronto, and University of Canterbury. All of these respondents were unaware of our study. We asked, "How much knowledge do you have on the BCG matrix for strategic planning in marketing?" Of the, 198 respondents, $36 \%$ had "a fair amount" or "ext ensive" knowledge. Only five percent claimed to have no knowledge of the BCG matrix.

\section{Difficulties in understanding NPV}

We expected that managers would use the BCG matrix because it provides a heuristic that is easy to understand and to apply. Similarly, one might expect subjects to be more likely to use a profit-oriented approach if it were easy to apply (many of our subjects said that they did not understand the present value approach). To test a profit-oriented heuristic, we conducted nine experimental administrations that contained a "payback version" as well as an NPV version. ${ }^{5}$ These groups were informed that they had attended a course on the payback period and they had notes stating that:

"The best way to analyze the probability of an investment is to use net present value (NPV). However, many managers do not have the patience or inclination to use NPV. A simple rule of thumb on return will produce results that are almost as good. Furthermore, the rule of thumb is more likely to be used. One popular rule of thumb is that the investment in a project should he completely repaid within five years. This "five-year payback" rule is suggested for firms when they must make a decision on investment projects."

for these experiments, $34.8 \%$ of the 112 subjects in the payback treatment made the unprofitable investment. This compares to $38.9 \%$ of the $119 \mathrm{NPV}$ subjects in these same administrations. The difference is in the expected direction, but it is small.

The payback method had a small impact relative to the control group (10.3\% fewer unprofitable decisions). ${ }^{6}$ In contrast, the BCG matrix had a larger effect relative to the control group (23.1\% more unprofitable decisions). Thus; it seems that the BCG matrix effect is not due simply to the ease with which the matrix is applied.

We speculate that decision makers use the BCG matrix because it legitimizes an intuition that many people have about business decisions. Simply stated, people believe that you should "stick with your winners" (best products). Some responses by control group subjects contained statements expressing this viewpoint. Subjects using the BCG matrix also said to "stick with past winners". For additional views on why the BCG matrix became so popular, see Morrison and Wensley (1991, pp. 115-116).

\section{Demand effects}

Were the results due to demand effects? One might argue that provision of the BCG matrix by an authority implies that it is relevant to solving the problem. Alternatively, subjects might have been obedient to a request by an experimenter. We examined the issue of demand effects in several ways.

\footnotetext{
${ }^{5}$ One experimental administration included payback but not NPV. Results from this administration were not included. Their inclusion would have had no impact on the conclusions.

${ }^{6}$ These comparisons were based only on the experimental occasions where payback was administered.
} 
We found some evidence in support of a demand effect by comparing results of undergraduate and MBA students. One would expect undergraduates to be more obedient. They were. In the New Zealand sample, undergraduates exposed to the BCG matrix were more likely to use it in their analysis; $74.3 \%(\mathrm{n}=82)$ did so versus $59.3 \%(n=54)$ for MBAs. Similarly, 68.3\% $(n=82)$ of those who received the NPV description used it in their analysis, in comparison with $60.4 \%(\mathrm{n}=48)$ of MBAs. However, another explanation of these results is that subjects who think that they have more expertise (the more experienced students) are less likely to use a decision aid; evidence for this latter explanation is provided in Arkes et al. (1986).

Arguing against demand effects is that the experimental situation is representative of situations faced by managers and prospective managers. They read about the $13 \mathrm{CG}$ matrix in textbooks, journals, and magazines. They might assume that the BCG matrix is presented by-authorities because it is relevant as an aid to decision making. Rather than being a demand effect, this represents the "educational effect" that we are trying to assess.

Another argument against demand effects is that we advised all subjects to maximize profits. The subjects were not highly obedient to that instruction. Furthermore, those in profit-oriented treatments were much less obedient than those in the BCG treatment.

Finally, we conducted additional experiments with 118 middle-management subjects. Here, we controlled for demand effects by giving control group subjects information on both profit-oriented and BCG procedures. These treatments were administered three times from May through October, 1990. Inas much as results from payback. and NPV treatments were nearly identical here, we combined these results. ${ }^{7}$ Of the BCG subjects, $61.9 \%$ chose the Star (Sunbars) decision. This result is similar to that observed earlier (see Table 1) where $63.5 \%$ of subjects chose the Star. The profit oriented subjects also responded in a similar way as previously; $30.6 \%$ selected the star versus $37.1 \%$ in the earlier studies. The control group is of primary interest in this test. Previously, when receiving no information, $45.7 \%$ had selected the Star. The present control group, with both BCG and profit techniques, selected the Star $60.0 \%$ of the times. This is comparable to the $61.9 \%$ Star selection by those receiving only BCG information. Thus, presence of a second "demand," to maximize profits, had negligible impact on decision making. These results, summarized in Table 3, support the conclusion that demand effects are unimportant.

Table 3

Decisions when the control group received both treatments

\begin{tabular}{llll}
\hline Treatment presented & Number of subjects & Selected Star & Percent Stars \\
\hline BCG & 42 & 26 & 61.9 \\
Control & 40 & 24 & 60.0 \\
Profit & 36 & 13 & 36.1 \\
\hline
\end{tabular}

Interaction of task and treatment

Although we had no hypotheses about in teraction effects, we did examine whether the nature of the situation, cost-saving or advertising, might affect results. To test this, we rewrote the situation so that Digits rather than Sunbars made the same amount of money through an advertising campaign. Conversely, Sunbars (.rather than Digits) had the opportunity for a cost-saving invention but, as before, the Sunbars project was unprofitable.

Reversal of the decision context did not affect results. In fact, these results were stronger than the previous ones. For the original description, $44 \%$ of the 45 subjects selected the unprofitable (Star) decision. For the reversed wording, $50 \%$ of the 62 subjects selected the Star. .

\section{Full information}

This study compared the BCG matrix to other decision-making methods in situations where the objective was clearly stated and full information was available to meet these objectives. If full information were not available, as one might expect in the real world, we think that results would be even stronger. That is, instead of using methods to maximize profits, decision makers would rely even more on the- matrix method.

\footnotetext{
${ }^{7}$ When the NPV was used for the profit-oriented version, the control group also received this version. When the payback period was used, we gave it also to the control subjects.
} 
Bias

A potential source of bias is that our subjects may have wanted to look good in the eyes of the experimenters (Sigall et al., 1970). Looking good here would seem to depend on guessing the hypotheses correctly. We asked two groups $(\mathrm{n}=23)$ to guess our hypotheses, after they had completed the experiment. None of their guesses was correct. This suggests that few subjects were trying to help (or hurt) the experimenters.

\section{Students as subjects}

We used students as subjects. Most subjects had a considerable amount of business experience, they had prior exposure to the BCG and NPV methods, and they were representative of people who face these types of decisions. This use of students as subjects is consistent with recommendations in Gordon et al. (1987). Finally, administrators reported that subjects took the task seriously. Most subjects spent over 20 minutes on the exercise, and they defended their decisions vigorously in debriefing sessions. Prior research, summarized by Ashton and Kramer (1980), found that studies of decision-making processes obtained similar results with student as with nonstudent subjects.

\section{Limitations}

The key limitation is whether subjects' decisions in this situation would be representative of what they would do in a real situation. While we tried to make the situation representative of a type of decision faced by managers, it is possible that the experiments were too simple-minded and too far removed from the real world. Funder (1987) claims that subjects in laboratory experiments often solve problems that differ from those that the experimenter had in mind. For example, subjects might have chosen the less profitable decision because they did not interpret profits in the same way as used by the experimenters. Although such interpretation problems are thought to be endemic to laboratory experiments, Locke (1986) found that laboratory experiments have a surprisingly high level of construct validity.

Did the experimenters create bias? We are not aware of any biases. One of the authors was an advocate of the BCG matrix at the beginning of this study. Also, opinions on the value of the BCG matrix varied among the six administrators, but only one initially thought that use of the BCG matrix was detrimental. As a further check on bias, we used advice from other BCG advocates during the design and pretest phases. Furthermore, on the follow-up questions and in debriefing sessions, subjects did not indicate that they had been misled.

We used Kotler because it is a widely read marketing textbook and because we thought that it provided a good description of the BCG matrix. It is possible that other descriptions of the BCC matrix would lead to different results. Also, more intensive training that examines limitations of the matrix might affect results.

Our study examined a situation in which a profit-maximizing approach and a matrix method yielded different conclusions, whereas in many situations the decisions implied by the two methods would be the same. Our study offers no insight on how often such conflicts might arise. However, Hambrick et al. (1982) found that more existing products were classified as Dogs than in any of the other categories. Furthermore, they found that many Dogs earned high profits. This implies that there are many situations in which the BCG marketing and profit maximizing approaches might conflict.

\section{Conclusions}

The BCG matrix has gained widespread acceptability over the past two decades. It is widely taught in marketing courses as a guide for product market decisions. Managers and potential managers reported in our surveys that they were familiar with the BCG matrix; of 198 respondents, two-thirds believed it to be an effective technique.

Assumptions underlying the use of the BCG matrix have been challenged. Even if one accepts the BC G matrix assumptions, one might question whether it is used properly. We were unable to find a single empirical study that demonstrated that the BCG matrix was valuable as a decision aid. 
Our study provides experimental evidence that the BCG matrix interferes with profit maximizing. Results were obtained in a test of extremes: a choice between an investment that allowed the company to double its investment, and one where half the investment was lost. Despite being faced with what we thought to be an obvious decision, subjects who were provided with information about the BCG matrix were easily misled. Only $13 \%$ of those who used the BCG matrix in their analysis invested in the more profitable project. The study was replicated and extended as six administrators obtained similar findings for 27 experiments covering 1015 subjects in six countries over a five-year period.

Our results support those from the field study by Capon et al. (1987). They suggest that detrimental effects of the BCG matrix (in misleading some decision makers) outweigh possible gains (e.g., additional insights, adding structure to chaos) that might be produced when firms use the matrix as a diagnostic aid.

Profit-oriented approaches, such as NPV, should play an important role in portfolio decisions. One should consider how decisions for a given product affect profits for the whole portfolio. However, we recommend that this be done without use of matrix methods.

Although we examined only the BCG matrix, we expect other matrix methods ${ }^{8}$ to interfere with profit making because of mental budgeting. We suggest that future research examine conditions under which mental budgeting might apply to portfolio methods. Until contrary evidence is produced, we advise against using matrix methods under all circumstances.

\section{References}

Arkes, H.R. and C. Bulmer (1985), "The psychology of sunk costs," Organizational Behavior and Human Performance 35,124-140.

Arkes, H.R., R.M. Dawes and C. Christensen (1986), "Factors influencing the use of a decision rule in a probabilistic task," Organizational Behavior and Human Decision Processes 37, 93-110.

Ashton, R.H. and S.S. Kramer (1980), "Students as surrogates in behavioral accounting research: Some evidence," Journal of Accounting Research 18,1-16.

Capon, N., J.U. Farley and J.M. Hulbert (1987), Corporate strategic planning. New York, NY: Columbia University Press.

Day, G. (1986), Analysis for strategic market decisions. St. Paul, MN: West.

Funder, D.C. (1987), "Errors and mistakes: Evaluating the accuracy of social judgment," Psychological Bulletin $101,75-90$.

Gordon, M., E.A. Slade and N. Schmitt (1987), "Student guinea pigs: Porcine predictors and particularistic phenomena," Academy of Management Review 12,160-163.

Griffin, R. and K.M. Kacmar (1991), "Laboratory research in management: Misconceptions and missed opportunities," Journal of Organizational Behavior 12, 301-3.11.

Hambrick, D.C., I.C. MacMillan and D.L. Day, (1982), "Strategic attributes and performance in the BCG matrix-a PIMS-based analysis of industrial product businesses," Academy of Management Journal 25, 510-531.

Haspeslagh, P. (1982), "Portfolio planning: Uses and limits," Harvard Business Review 60 (1), 58-73.

Hax, A. and N.S. Majluf (1983), "The use of the growth-share matrix in strategic planning," Interfaces 13, 46-60.

Jacobson, R. and D. Aaker (1985), "Is market share all that it's cracked up to be?" Journal of Marketing 49,11-21.

${ }^{8}$ This includes refined BCG methods such as those described by Hax and Majluf (1983). 
Kotler, P. (1984), Marketing Management. 5th ed. Englewood Cliffs, NJ: Prentice-Hall.

Locke, E.A. (ed.) (1986), Generalizing from Laboratory to Field Settings. Lexington, MA: Lexington Books.

McKiernan, P. (1992), Strategies of Growth: Maturity, Recovery and Internationalization. Routledge Series in Analytical Management.

Morrison, A. and R. Wensley (1991), "Boxing up or boxed in? A short history of the Boston Consulting Group share/growth matrix," Journal of Marketing Management, 7, 105-129.

Sigall, H., E. Aronson and T. Van Hoose (1970), “The cooperative subject: Myth or reality?” Journal of Experimental Social Psychology 6, 1-10.

Tversky, A. and D. Kahneman (1981), “The framing of decisions and the psychology of choice,” Science 211, 453-458.

Verhage, B.J. and E. Waarts (1988), "Marketing planning for improved performance: A comparative analysis," International Marketing Review 5, 20-30.

Wensley, R. (1981), “Strategic marketing: Betas, boxes, or basics?” Journal of Marketing 45, $173-181$.

Wind, Y. and V. Mahajan (1981), "Designing product and business portfolios," Harvard Business Review 59 (1), 155-165.

Wind, Y., V. Mahajan and D.J. Swire (1983,) “An empirical comparison of standardized portfolio models,” Journal of Marketing 47, (Spring), 89-99.

Zallocco, R.L., D.W. Scotton and DA. Jeresko (1983), "Strategic market planning in the commercial airline industry," Journal of the Academy of Marketing Science 11, 404-416. 